\title{
ATTENTION AND COGNITION
}

\section{PRENATAL MARIHUANA, CIGARETTES, ALCOHOL AND ATTENTIONAL BEHAVIOR}

A follow-up study of intentional behavior in 6 year old children exposed prenatally to marihuana, cigarettes and alcohol is reported from the Department of Psychology, Carleton University, Ottawa, Ontario, Canada. Discriminant function analysis in 126 children revealed a dose response association between prenatal cigarette exposure and impulsive behavior. Performance on memory tasks requiring verbal recall was negatively associated with maternal cigarette use. Prenatal marihuana was associated with omission errors in vigilance tasks reflecting a deficit in sustained attention. The mother's rating of impulsive hyperactive behavior was also higher. Low levels of maternal alcohol consumption were related to decreased impulsive responding, assessed by mothers' reports by mothers reports (Fried PA et al. A follow-up study of attentional behavior in 6-year-old children exposed prenatally to marihuana, cigarettes, and alcohol. Neurotoxicol Teratol Sept/Oct 1992; 14:299-311). (Reprints: Dr. Peter A. Fried, Department of Psychology, Carlton University, Ottawa, Ontario, Canada K1S 5B6.)

COMMENT. No negative relationship between prenatal alcohol exposure and attention related variables was noted in this study. The only differences related to maternal alcohol consumption were in decreased impulsivity: fewer responses were made in the delay tasks and a decreased degree of impulsivity/hyperactivity in the child was reported by the mother. Others have reported an increased reaction time associated with maternal alcohol consumption in 4 and 7 year old children on vigilance tasks. The timing of the exposure to the alcohol was not determined in this present study, and relatively low levels of alcohol were consumed by the mothers. This could account for the absence of negative association between attentional behavior and maternal alcohol use.

\section{CONGENITAL DEGENERATIVE DISORDERS}

\section{RETT SYNDROME: GROWTH AND NUTRITION}

Feeding problems, dietary intake and the growth and nutrition of 10 girls with Rett syndrome were reported from the University of Oslo, Norway. All patients had birth weight and length within the normal range until 6 to 24 months of age. A fall off in linear growth occurred in the first 2 years of life, and at follow-up between 3 and 16 years of age, all but 1 had height and/or weight below the 2.5 percentile of healthy children. Oral-motor dysfunctions were common. The mean energy intake was $70 \%$ of the U.S. recommendations according to age and $108 \%$ according to body weight. The intakes of thiamin, vitamin D, calcium and iron were low. None was anemic (Thommessen $M$ et al. Growth and nutrition in 10 girls with Rett syndrome. 